\author{
АНДРЕЙ АХМЕТОВИЧ ЗАЙНУЛЬДИНОВ \\ Uniwersytet Barceloński \\ andrei.zainouldinov@ub.edu
}

\title{
Значение внутренней формы слова при формировании эмотивной оценочности русской субстандартной лексики и фразеологии ${ }^{1}$
}

В настоящей статье предлагается анализ лексико- и фразеографического описания эмотивно-оценочных (эмоционально-оценочных) языковых единиц современного русского жаргона (субстандарта), предложенного автором в рамках создаваемого им Словаря эмоционально-оценочной русской лексики и фразеологии (ЭМОС). Картотека части словаря, включающего единицы жаргона, составлена из эмотивно-оценочных единиц, собранных автором на основе использования данных теории речевого воздействия (Киселева, 1978), был использован также иллюстративный материал Словаря московского арго В.С. Елистратова, Большого словаря русского жаргона B.М. Мокиенко и Т.Г. Никитиной. Под субстандартной лексикой вслед за А.К. Бирих понимаются некодифицированные разновидности разговорной речи (просторечие, жаргон и арго) (Бирих, 2000: 34).

В последнее время стала популярной идея представления данной подсистемы языковых единиц, маркированной в экспрессивном, национальном и стилистическом плане, в связи с активно формирующимися категориями лингвокультурологии. Обращение к практическому описанию лексической и фразеологической подсистем русского субстандарта позволяет не только представить семантические и лексикографические критерии классификации материала, но и уточнить некоторые положения современной прагмалингвистики.

${ }^{1}$ Данная работа осуществлена при поддержке и в рамках проекта DIANACONSTRUCCIONES: BUSCANDO EL CONOCIMIENTO OCULTO EN LOS TEXTOS Иcпанского министерства экономики и развития. 
Существует значительное число косвенных указаний на оценочное значение компонентов фразеологических единиц: «кровь с молоком - Белое лицо и румянец - красота, свидетельство хорошего здоровья, отсюда положительная тональность выражения» (Фелицына, Мокиенко, 1990: 77); «видеть (все) в розовом (радужном) свете - Розовый цвет ассоциировался с добрым здоровьем и благополучием, с благодушием и совершенством» (Бирих, Мокиенко, Степанова, 2001: 519).

Специфика прагмалингвистического подхода, основанного на речевом воздействии, определяет существование собственных критериев классификации в рамках семантической теории понимания образности как «чувственной наглядности» (Потебня, 1958: 18). Языковая информация представляет собой передаваемое в разных коммуникативных целях средствами языка (или речи) содержание, отображающее не только собственноинтеллектуальные (когнитивные) понятия, суждения, умозаключения, но и эмоциональные концепты (в самом широком смысле), в которых находят отражение эмоциональные, эстетические оценки носителей языка, их побуждения и контактные устремления.

Нельзя не согласиться с А. Вежбицкой, считающей эмоциональность одной из наиболее важных семантических характеристик, образующие смысловой универсум русского языка. При этом под эмоциональностью понимается «ярко выраженный акиент на чувствах и на их свободном проявлении, высокий эмоциональный накал русской речи, богатство языковых средств для выражения эмоций и эмоцчиональных оттенков» (Вежбицкая, 1996: 33-34).

В образной семантике компонентов ЛЕ и ФЕ объединяются прагматические (в том числе эмотивные, отражающие эмотивное мышление) и предметно-логические аспекты значения. Именно осознание образной мотивации (либо ее подчеркнутой бессмысленности) определяет возможность «заражения» (Выготский, 1956) адресата интенцией субъекта оценки. Невыводимость оценочной семантики из номинативного компонента значения лексем представляет собой характерную черту данной лексической подсистемы, определяет маркированность лексических единиц с эмоциональной оценкой.

По мнению автора, именно осознание внутренней формы ЛЕ и ФЕ является связующим звеном, позволяющим вызвать соответствующее представление адресата на базе его собственных эмоциональных реакций (см. Wierzbicka, 1992), адекватное интенции субъекта, при этом ЛЕ (ФЕ) служат психическим раздражителем словесного плана.

Автором выделены следующие собственно-семантические маркеры, обусловливающие возникновение/наличие эмотивной оценочности:

- высокая степень интенсивности выражаемого признака ЛЕ, его гиперболизированность: караульныци - 'прил. (жарг.) одобр./восх. Очень хороший, прекрасный. Караульная квартирка', етитский — 'прил. (жарг.) 
неодобр. Общий эпитет, выражающий эмоциональное (обычно отрицательное) отношение говорящего к объекту. Етитское правительство', клинический - 'прил. (жарг.) неодобр. перен. Излишний, чрезмерный, ненормальный. Клинический идиот';

- метафорический перенос (при «живой» образности ЛЕ (ФЕ) и их составляющих на синхронном уровне, свежести языковых единиц за счет неожиданных ассоциаций с чувственно-наглядными представлениями, яркими визуальными, вкусовыми ощущениями): изжога — 'сущ. м. (жарг.) неодобр. перен. Что-либо нудное, неприятное, неинтересное. Изжога мексиканская (о телесериале)', атараксия - '1. сущ. ж. (жарг.) одобр. и ирон. Любое приятное состояние. Чайку похлебал-пришёл в атараксию. 2. в 3н. межд. (жарг.) одобр. Выражает любую положительную эмоцию. Вчера вечером оттянулись как следует. Атараксия!', творческий климакс - '(жарг.) неодобр. Неспособность что-либо делать, отсутствие вдохновения, хандра', классика рока - '(жарг.) восх. Что-либо отличное, замечательное; что-либо общепризнанное, неоспоримое';

- подчеркнутая затемненная мотивированность образной семантики (созданная при образовании ФЕ на контрасте стилевой принадлежности компонентов, либо возникшая в результате утраты мотивированности значения образной структуры на синхронном уровне): байда - 'сущ. ж. (жарг.) неодобр. перен. Ерунда, чушь', бепек - 'сущ. м. (жарг. бран.) крайнее неодобр. Нехороший человек, преимущественно употребляется как ругательство', каля-маля - '1. сущ. ж. (жарг.) неодобр. перен. Мазня, пачкотня. 2. сущ. ж. (жарг.) неодобр. перен. Неразборчивый, небрежный рисунок, почерк'.

Собственно образное значение слова является компонентом лексической семантики, передающим сопутствующие представления. Интегральный характер образности обусловливает как денотативное (номинативное), так и коннотативное (прагматическое) содержание.

Данная трактовка восходит к русской филологической традиции (работам А.А. Потебни, Д.Н. Овсяннико-Куликовского, Л.П. Якубинского и др.), а также концепциям В. Гумбольдта, Ш. Балли, рассматривавшим понятие внутренней формы слова как ассоциативно-образный мотив при выделении психологической данности представления, вызывающего соответствующий образ на основе его языковой мотивированности: «внутренняя форма, кроме фактического единства образа, дает еще знание этого единства; она есть не образ предмета, а образ образа, то есть представление» (Потебня, 1999: 125). На особую роль мотивации в языке указывали также ряд зарубежных исследователей (Pastor, 1996: 121; Lakoff, Johnson, 1980; Lakoff, 1987).

Сущность семантической мотивированности заключается в уподоблении двух предметов по общему для них признаку, при этом признак называется опосредованно, через образ-символ, существующий в языковом сознании носителей данного языка как воплощение этого признака (мета- 
форический перенос, ассоциативные характеристики). Существенно замечание о том, что корни языковой образности лежат не в семантике, а в тезаурусе, в системе значений (Black, 1962).

Таким образом, образность представляет собой семантический компонент, отражающий ассоциации (представления), связанные с определенным словом, а через него и с конкретным признаком, явлением, называемым данным словом. Необходимо уточнить, что свойства, закрепленные за образным значением слова, могут быть предполагаемыми или переосмысленными. Специфика образности как средства создания экспрессивности обусловливает наличие коннотативных сем (в том числе эмоциональной оценочности), наслаивающихся на денотативное значение, в связи с чем эмоционально-оценочная образность, определяющая предикацию, обладает повышенной поражающей силой.

Нельзя не отметить принципиально важный аспект значимости внутренней формы при создании образности, представленный в работе В.Н. Телии посвященной фразеологической семантике (Телия, 1996). В лингвистический обиход было введено еще одно измерение - эпидигматическое, оперирующее ассоциациями, которые мотивируют вторичные значения слов. Реальность того, что без учета внутренней формы невозможно описать лексическое значение экспрессивных единиц, убеждают в том, что образность, заключенная во внутренней форме, как раз во многом и предопределяет не только развитие значения, но и особенности его функционирования.

Введение эпидигматического измерения и осознание важности мотивационного основания фразеологизмов-идиом определили необходимость исследовать саму образную структуру внутренней формы - ее метафорический, метонимический и т. п. характер, а также роль в ней различного рода символов или квазисимволов (ср., например, квазисимвольное прочтение слова рука в идиомах, где этот компонент ассоциируется с идеей власти: держать в руках, иметь руку), а также эталонов или квазиэталонов (типа дрожать над каждой копейкой, от горшка два вершка) (Телия, 1996: 45). Все вышеизложенное относится не только к фразеологической, но и к лексической образной семантике.

Учитывая образную структуру внутренней формы ЛЕ и ФЕ, можно выделить интегральные образные семы отнесенности компонентов первичной номинации, обусловливающие характер эмотивной оценочности, по крайней мере, при разграничении пейоративного и мелиоративного (= позитивного и негативного) плана. Данные семы опираются на подчеркнутое, выделенное, экспрессивно маркированное отклонение от нормы. Эта отнесенность в определенной степени отражает эмотивно-оценочные культурно-мифологические представления русских (гештальты), зафиксированные в словесной форме и может быть представлена в рамках ФСГ 
(= функционально-семантических групп), объединяющих ЛЕ и ФЕ, которые выражают эмотивную оценочность определенного плана.

Типичную ФСГ с пейоративной оценочностью представляют ЛЕ и ФЕ, соотнесенные с семантикой «деревянного», при этом в жаргоне происходит естественное расширение перечня наименований: бамбуковый — 'прил. (жарг.) пренебр. перен. Глупый, тупой, недогадливый. Tы сам бамбуковыій или у тебя папа деревянный?', баобаб - 'сущ. м. (жарг.) крайнее неодобр. перен. Глупый человек, тупица'; здравствуй, африканское дерево — '(жарг.) неодобр. Глупый человек, тупица, бездарь.' Другие ФСГ с пейоративной оценочностью представлены наименованиями, соотнесенными с «пустотой»: nустая кастрюля - '(жарг.) неодобр. Дурак, пустой человек', пустырь - 'сущ. м. (жарг.) неодобр. перен. Двоечник; тупой, несообразительный ученик', пустылику гнать - '(жарг.) неодобр. Болтать пустое, лить воду'); «хаотичностью»: базар - 'сущ. м. (жарг.) неодобр. перен. Беспорядок, неразбериха, сумятица'; «звоном»: звонок - 'сущ. м. (жарг.) неодобр. перен. Пустой человек; пустозвон; трепач, лгун', звякало - 'сущ. с. (жарг.) неодобр. Слишком разговорчивый человек, болтун, пустомеля'); «мусором»: веник - '1. сущ. м. (жарг.) неодобр. перен. Простой, примитивный человек. 2. сущ. только мн. (жарг.) неодобр. перен. Ерунда, безделица, чушь. Опять какие-то веники несет', мусор - 'сущ. м. (жарг.) неодобр. перен. Милиционер', ветошь - 'сущ. ж. (жарг.) неодобр. перен. Простачок, шалопай. Ветошью прикинуться.'

Не менее значительными по объему являются широко представленные также в стандарте русского языка: ФСГ «пресмыкающихся»: анаконда 'сущ. ж. (жарг.) неодобр. перен. Жена. Днем я работаю, а ночью меня моя анаконда душит', змея - 'сущ. м. (жарг.) неодобр. ирон. перен. О жене или теще'; ФСГ «земноводных»: жаба - 'сущ. м. (жарг.) неодобр. перен. Некрасивая женщина', головастик - '1. сущ. м. (жарг.) неодобр. перен. Маленький, невзрачный человек. 2. сущ. м. (жарг.) неодобр. перен. Ироническое обращение'; ФСГ «обезьян»: бабуин - 'сущ. м. (жарг.) неодобр. пренебр. перен. Женщина', гиббонистый — 'прил. (жарг.) неодобр. перен. Некрасивый, нескладный'; ФСГ «насекомых-паразитов»: гнида — 'сущ. м. (жарг.) крайнее неодобр. перен. Ругательство', вощь - 'сущ. ж. (жарг.) неодобр. перен. Ничем не примечательный человек. Что это там за вошь ползет, натюрморт портит. 3. сущ. ж. (жарг.) неодобр. перен. Нечто маленькое, незначительное'; ФСГ «лесных животных»: бурундук — 'сущ. ж. (жарг.) неодобр. перен. Жадный человек; скопидом, все несущий домой', вырра '1. сущ. ж. (прост./разг. бран.) неодобр. перен. О некрасивой и худой женщине. 2. сущ. ж. (жарг.) неодобр. перен. Некрасивая, неприятная женщина. Не кассирма, а вылра болотная'; ФСГ «продуктов питания»: антрекот 'сущ. м. (жарг.) неодобр. и шутл. перен. Толстяк', гулям - 'сущ. м. (жарг.) неодобр. перен. Толстый, тучный человек. Гляди, какой гуляи идет’, батон 
— 'сущ. м. (жарг.) неодобр. Странный, нелюдимый, не имеющий друзей человек (чаще о подростке)'.

Принцип антропоцентризма, определяющий границы аксиологической зоны выбора первичных наименований для переосмысления, определяет также доминирование единиц, характеризующих человека: ваучер - 'сущ. м. (жарг.) неодобр. перен. Партнер (чаще о плохом, ненадежном)', авосьник - 'сущ. м. (жарг.) пренебр. Человек, делающий все «на авось», халтурщик, ненадежный человек', либо частей его тела: грабли — 'руки', будка — 'голова; лицо', брехало, вякалка - 'рот'. Реже при оценочной номинации подобным образом характеризуются предметы или ситуации: калоша - 'сущ. м. (жарг.) неодобр. перен. Старая машина', гадюшник - 'сущ. м. (жарг.) неодобр./пренебр. перен. Какое-либо низкопробное, сомнительное заведение; любое грязное, запущенное место; любое заведение, место. В моем гадюшнике все без изменений (у меня на работе)', вешалка — 'сущ. ж. (жарг.) неодобр. перен. Трудная ситуация; что-либо плохое, нежелательное; то, что может привести к отрицательному результату. Нет, ребята, пиво на вино это - вешалка'.

Наряду с традиционными источниками формирования оценочной семантики (мир животных; неодушевленных предметов, окружающих человека в повседневной жизни) выделяются источники, типичные для формирования оценочной семантики в современном субстандарте. Среди последних следует отметить:

- метафорические наименования, значение которых сформировано на базе иронического переосмысления персонажей художественных произведений для детей: айболит - 'садист, жестокий человек', бармалей - 'неприятный человек', буратино - 'полный дурак, идиот, тупица', карлсон - 'несчастный, забитый, невзрачный человек';

- экзотизмы: какаду — 'дружеское обращение', икебана — 'порядок, чистота; хорошая обстановка в квартире, красивый интерьер', брахмапympa - 'нечто сложное, запутанное, трудно разрешимое';

— иностранные слова: полный безандестенд — 'о тупом, недогадливом человеке, который не понимает чего-либо', бейба - 'ласково-шутливое обращение'.

Последние две группы также соответствуют принципу семантической немотивированности как источнику формирования оценочной семантики.

Значительную группу среди источников формирования оценочных единиц представляют имена собственные, при этом мелиоративность (при обязательной ироничности) создается на основе использования имен актеров, в сознании языкового коллектива воспринимаемых как образцов красоты, мужественности: Ален Делон - 'ирон. Красивый, видный мужчина', Бельмондо - 'ирон. Человек с претензией на особую красоту, силу и т.п.)', спортсменов, политических деятелей как символов решительности: Жаботинский — 'Большой, сильный человек', Железняк — 'Решитель- 
ный, надежный человек'. Интересен пример, отражающий возникновение собственно-оценочного значения: бенилюкс — 'сущ. м. также в знач. сказ. одобр./восх. перен. Что-л. высокого качества'. Пейоративно оцениваются представители авторитарного правления (Аракчеев — 'классный руководитель; директор школы'), политические лидеры (Дзержинский — 'ирон. обращение', Горбатый — 'М.С. Горбачев; обманщик, фантазер', Касторкин - ‘Фидель Кастро'). При этом необходимо отметить, что важным аспектом выбора первичных наименований являются оценочные ассоциации и аналогии языкового сознания (Жаботинский - жаба, Железняк - железный, Бенилюкс - люкс, Горбачев - горб, Касторкин - касторка).

Особую группу представляют собой имена (в основном мужские) с ярко выраженной пейоративной оценочностью: Алёша — 'очень глупый, тупой человек', Ванька с Пресни - 'простой, незатейливый, недалекий человек', Дунька с мыльного завода - 'неотесанная, необразованная, обычно провинциальная женщина; также негативно воспринимаются оценочные единицы на основе иностранных имен: Додик — 'маленький, тщедушный, хилый, глупый человек; любой человек, о котором говорится с пренебрежением', Жоржик — 'пижон, франт, модник; сын богатых родителей, неженка, капризный человек'.

Интересны примеры переносных метафорических значений явлений социальной сферы, при этом основой возникновения вторичного оценочного значения является не столько оценивание человека через сопоставление с физическими характеристиками предмета, сколько ассоциативные представления языкового сознания, связанные с первичными наименованиями (так называемые квазистереотипы). Непрестижность в языковом сознании определенной профессиональной или социальной принадлежности определяет пренебрежительную оценочность таких единиц, как сельский агроном - '(жарг.) пренебр. ирон. перен. О человеке, который хочет показать, что он умный', дворник - '1. сущ. м. (жарг.) неодобр. перен. Недотепа, растяпа. 2. сущ. м. (жарг.) неодобр. перен. Ироническое обращение', доктор — '1. сущ. м. (жарг.) неодобр. перен. Недалекий, глупый, несообразительный человек', инженегр — 'сущ. м. (жарг.) неодобр. ирон. перен. Инженер'.

Многие оценочные единицы опираются на яркие наглядные образы вкуса, запаха, осязания, что, в свою очередь, помогает вызвать соответствующие эмоции у адресата. Однако и в этих случаях первичной основой для возникновения оценочных значений являются потенциально оценочные представления, объединенные в ФСГ. Примерами подобной закономерности формирования пейоративной семантики являются эмотивно-оценочные наименования, отражающие сферы социально неприемлемого (табуированного): «неприятного запаха» (вонючий — 'плохой, дурной; такой, который ниже достоинства говорящего', занюханный — 'ничтожный, мелкий; малокультурный, провинциальный'), «возбудителей болезни» (бледная спирохета — 'тощий, бледный, немощный человек', бактерия — 'против- 
ный, вредный человек'), «болезней» (даун - 'неинтересный, ненормальный человек; тупица, дурак, посредственность, зануда', геморрой — 'что-л. тяжелое, нудное, случайное, неприятное'), «табуированных физиологических реакций» (рыгательный — 'дурной, плохой, низкокачественный (о пище и др. вещах)', соплеглот - 'слабохарактерный, малодушный человек'), «смерти» (гробовой - «безнадежный, беспросветный», катафалк — 'автомобиль (обычно старый, плохой)').

Неожиданная новизна речевых переосмыслений определяет шутливую иронию стеба, отсутствующую в первичных наименованиях, которая становится основой иллокутивного эффекта: краснознаменный — 'косный, кондовый; плохой, глупый (о человеке)', безлошадный — 'плохой, глупый, убогий; обделенный чем-либо (о человеке)', богадельня — 'ироническое название любого заведения (кинотеатра, ресторана), преимущественно невысокого разряда'.

Снижается патетичность высокого стиля единиц кодифицированного языка: воин — 'ироническое обращение солдата к солдату', деятель — 'излишне активный, общительный, деятельный, предприимчивый человек, обычно неодобр.', акын - 'болтун, пустомеля, трепло. Акыны кремлевские'.

Представляется системной закономерность развития общеоценочного значения на базе номинативно-оценочной семантики (прежде всего - для единиц с мелиоративной оценочностью): вкуснячка - от '1. нечто вкусное' к '2. нечто хорошее, качественное'; катарсис — от '1. что-либо приятное, отличное' к '2. в зн. межд. выражает любую положительную эмоцию'; восторг — от '1. нечто отличное, замечательное' к '2. в значении междометия, выражает положительную эмоцию’. В результате этого процесса в жаргоне существует значительное число единиц с общеоценочной семантикой: академичный — 'хороший, прекрасный', академическая тефтелина — 'хорошая вещь', кашемир — 'что-либо хорошее, отличное, высочайшего качества', кака — 'что-либо плохое, некачественное, отрицательно оцениваемое'.

Данный процесс двусторонен: расширяется круг признаков, по которым может быть оценен объект/адресат, а также круг объектов оценки (калоша - '1. растяпа, дурак', '2. друг, приятель', ‘3. старая машина'; баланда — '1. любая пища невысокого качества (обычно о еде в предприятиях общепита)', '2. бестолковый текст; неясная, нечеткая речь', бордель '1. любое сомнительное заведение', ‘2. вечеринка, попойка', ‘3. неразбериха, путаница, суматоха'). Появляются возможности предикативного использования ФЕ для оценки адресата, объекта, признака, ситуации в целом: вещь — '1. нечто очень хорошее', '2. выражает одобрение, восхищение, восторг', шик - блеск - красота — 'прекрасно, ну и ну, ай да вещь!'

Выражение иронического отношения также представляет собой системную характеристику субстандарта. Ироническая семантика может формироваться на основе неправильной формы, варианта произношения (правописания): бамажка, бельмонда, дирюга, дерёвня, замечаточный, ку- 
люторныци. Ирония определяет оценочную актуализацию за счет определений: гений в трусиках / гений среди удобрений - 'человек, слишком высоко себя ставящий, зазнайка', геракл засушенный/ геракл сушеный — 'ирон. обращение к человеку, который необоснованно считает себя физически сильным', герой - штаны с дырой - 'ирон. о человеке, который совершает какие-л. смешные поступки’; данная ироническая семантика может закрепляться в языковом значении: каратист - 'ирон. о человеке (обычно слабом, невзрачном), который лезет в драку; забияка, задира', балерина 'ирон. молодая, красивая женщина или девушка'.

Можно утверждать, что сквозная ирония, пронизывающая весь пласт лексики и фразеологии современного субстандарта, а также выражение шутливой насмешливости при максимально смягченной пейоративной оценочности отражают интенцию стеба - незлобного подшучивания, мягкой формы издевки (см. об арсенале «смеховой культуры» (Walter, Мокиенко, 2002: 306). Данная особенность определяет не только ядерную часть эмотивно-оценочных единиц, но периферию эмотивной оценочности: абажур — 'голова', бельведерка — 'стройная, красивая девушка', восьмидераст 'представитель поколения восьмидесятых'.

Следует отметить сложность лексикографической эмоционально-оценочной маркировки лексических, а также фразеологических субстандартных единиц, обусловленную синкретичным характером семантики, в таких случаях в положительном регистре автором используется смешанная помета одобр./восх., в отрицательном - пренебр./презр.

Безусловно, детальный анализ предлагаемого автором Словаря эмоиионально-оценочной русской лексики и фразеологии выходит за рамки настоящей статьи, тем не менее изложенное здесь позволяет ввести и определить некоторые семантические различия лексических и фразеологических единиц субстандарта в аспекте прагмалингвистики, что может быть использовано в практике лексикографического описания (одноязычных и двуязычных словарей), а также при преподавании русской лексикологии и практической стилистики на продвинутых этапах обучения.

\section{Библиография}

Black M., 1962, Models and Metaphors, [w:] Studies in Language and Philosophy, Ithaca, N.Y, c. $25-47$.

Lakoff G., 1987, Women, Fire and Dangerous Things: What Categories Reveal about the Mind, Chicago.

Lakoff G., 1980, Johnson M., Metaphors We Live By, Chicago.

Pastor G., 1996, Manuel de fraseología española, Madrid.

Walter H., 2002, Мокиенко В., Пословищь в современной русской речи и жаргоне, „Slavica Wratislaviensia" CXVIII, c. 303-309.

Wierzbicka A., 1992, Semantics, Culture and Cognition: Universal Human Concepts in CultureSpecific Configurations, New York. 
Бирих А., 2000, Фразеология в русском и хорватском субстандарте, „Słowo. Tekst. Czas” VI, Szczecin-Greifswald.

Бирих А.К., Мокиенко В.М., Степанова Л.И., 2001, Словарь русской фразеологии. Историкоэтимологический справочник, Санкт-Петербург.

Вежбицкая А., 1996, Русский язык, [w:] Язык. Культура. Познание, Москва, с. 33-88.

Выготский Л.А., 1956, Мышиение и речь. Психологические исследования, Москва-Ленинград.

Елистратов В.С., 1994, Словарь московского арго, Москва.

Киселева Л.А., 1978, Вопросы теории речевого воздействия, Ленинград.

Мокиенко В.М., Никитина Т.Г., 2000, Большой словарь русского жаргона, Санкт-Петербург.

Потебня А.А., 1958, Мысль и язык. Собрание трудов, Москва.

Телия В.Н., 1996, Русская фразеология. Семантический, прагматический и лингвокультурологический аспекты, Москва.

Фелицына В.П., Мокиенко В.М., 1990, Русские фразеологизмы, Москва.

\section{Value of the internal form of the word in the formation of emotional evaluative Russian substandard vocabulary and phraseology}

\section{Summary}

The present work investigates the pragmatic aspect of meaning based on Russian vocabulary and phraseology with positive and negative emotional evaluation. Such kind of investigation helps to resolve various problems with lexicographical marks and to create a new improved system of expressive marks. The author thinks that emotional evaluation can be defined with quite objective characteristics. It is offered the new type of classification based on GLT (lexical-thematic groups).

Keywords: semantics, pragmatics, substandard, emotional evaluation, Russian lexis and phraseology, lexicography.

\section{Znaczenie wewnętrznej formy słowa w kształtowaniu emotywnej oceny rosyjskiej substandardowej leksyki i frazeologii}

\section{Streszczenie}

Niniejsza praca poświęcona jest analizie pragmatycznego aspektu znaczenia w oparciu o rosyjskie słownictwo i frazeologię z pozytywnym i negatywnym wartościowaniem. Taki rodzaj analizy pomaga w rozwiązywaniu różnych problemów natury leksykograficznej oraz tworzeniu nowego ulepszonego systemu wyznaczników ekspresywnych. Autor uważa, że wartościowanie emocjonalne może być definiowane obiektywnie.

Stowa kluczowe: semantyka, pragmatyka, substandard, ewaluacja emocjonalna, leksyka i frazeologia rosyjska, leksykografia. 